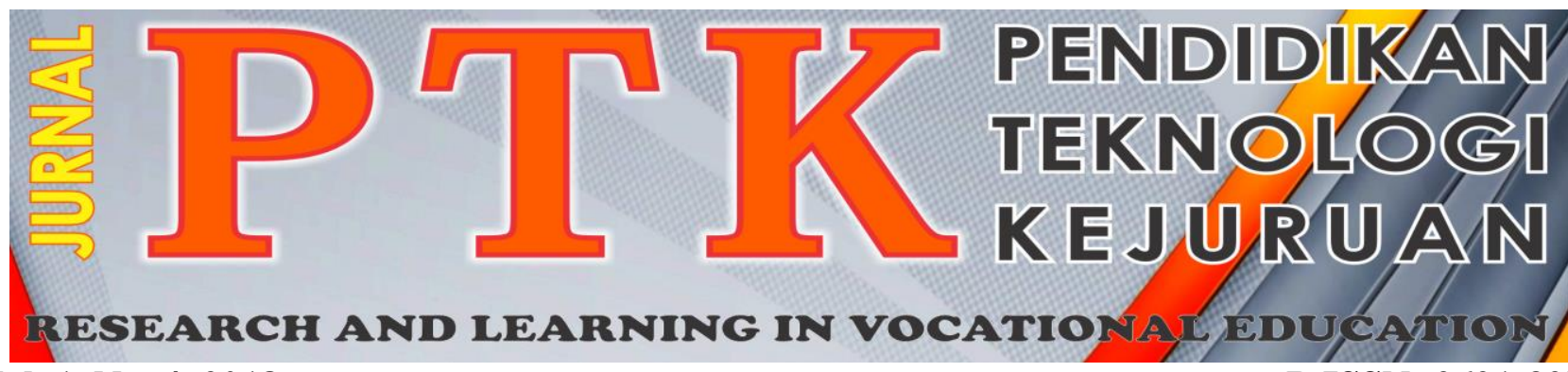

Vol. 1, No. 4, 2018

P-ISSN: 2621-3273

E-ISSN: 2621-1548

\title{
Studi Penyebaran Kontaminan Logam Berat Timbal (Pb) dan Merkuri (Hg) dari Air Lindi terhadap Air Sungai (Studi Kasus TPA Regional Kota Solok)
}

\author{
Dian Pratiwi ${ }^{1}$ dan Eka Rahmatul Aidha ${ }^{2}$ \\ Teknik Lingkungan, Sekolah Tinggi Teknologi Industri (STTIND) Padang \\ ${ }^{*}$ Corresponding author, e-mail: tulis dianpratiwi9268@yahoo.com ${ }^{1}$
}

\begin{abstract}
Abstrak - Tempat Pemrosesan Akhir Sampah (TPA) merupakan tempat untuk menampung pembuangan sampah dari berbagai lokasi, yang biasa cakupannya adalah satu kota. Penyingkiran dan pemusnahan sampah ke dalam tanah merupakan cara yang selalu digunakan, karena biaya relatif murah, pengoperasiannya mudah dan luwes dalam menerima limbah. Setiap TPA memiliki karakteristik air lindi yang berbeda tergantung dari proses yang terjadi di dalam landfill, yang meliputi proses fisika, kimia dan biologis. Umumnya lindi mengandung Chemical Oxygen Demand (COD), Biology Oxygen Demand (BOD), Total dissolved solids (TDS), total organic carbont (TOC), senyawa nitrogen nitrogen dan berbagai jenis logam berat yang tinggi. Parameter pencemar yang di tinjau pada penelitian ini adalah timbal $(\mathrm{Pb})$ dan Mercury $(\mathrm{Hg})$. Untuk mengetahui penyebaran kontaminan, pada penelitian dilakukan permodelan matematis timbal $(\mathrm{Pb})$ dan Mercury (Hg) dengan munggunakan model analitik 1-dimensi dan 2 dimensi berdasarkan persamaan adveksi dan dispersi pada air tanah dan air permukaan. Penelitian ini dilakukan di sungai sawah lansek yang merupakan badan air tempat mengalirnya lindi dari TPA regional kota solok. Konsentrasi timbal $(\mathrm{Pb})$ dan Mercury $(\mathrm{Hg})$ diukur pada 3 titik, dari hasil pengukuran tersebut diketahui bahwa sawah lansek memang tercemar oleh lindih TPA yang dilihat dari konsentrasi timbal (Pb) dan Mercury (Hg) yang sudah melebihi baku mutu. Simulasi dari timbal $(\mathrm{Pb})$ dan Mercury $(\mathrm{Hg})$ menunjukkan semakin lama waktu (t), input polutan yang konstan membuat beban kontaminan semakin besar. Akibatnya konsentrasi kontaminan pada $t$ yang lebih besar akan mengalami penurunan yang lebih jauh. Hasil simulasi konsentrasi timbal (Pb) dan merkuri (Hg) telah mencapai jarak $\pm \mathbf{1 0 0}$ Meter dari TPA kontaminan terus menyebar seiring bertambahnya umur TPA, kontaminan timbal $(\mathrm{Pb})$ dan mercury $(\mathrm{Hg})$ telah mencapai sungai Batang Lembang yang berjarak \pm 2500 Meter dari TPA, dan mengalami penurunan pada jarak yang lebih jauh.
\end{abstract}

Kata kunci: TPA, lindi, Timbal, Merkuri, Adveksi, Dispersi

Abstract-Landfill is a place to relocate garbage disposal from various locations, the usual coverage is one city. Removal and destruction of waste into the ground is a method that is always used, because the cost is relatively cheap, the operation is easy and flexible in receiving waste. Each landfill has different characteristics of leachate depending on the processes that occur in landfills, which include physical, chemical and biological processes. Generally leachate contains Chemical Oxygen Demand (COD), Biology Oxygen Demand (BOD), Total dissolved solids (TDS), total organic carbont (TOC), nitrogen nitrogen compounds and various types of high heavy metals. The pollutant parameters reviewed in this study were lead $(\mathrm{Pb})$ and Mercury $(\mathrm{Hg})$. To determine the spread of contaminants, the research carried out mathematical modeling of lead $(\mathrm{Pb})$ and Mercury $(\mathrm{Hg})$ by using a 1-dimension and 2-dimension analytic model based on advection and dispersion equations in groundwater and surface water. This research was carried out in the river rice field landscape, which is a body of water where leachate flows from the city solok landfill. The concentration of lead (Pb) and Mercury $(\mathrm{Hg})$ is measured at 3 points, from the measurement results it is known that the field rice fields are indeed contaminated by landfill leach seen from the concentration of lead $(\mathrm{Pb})$ and Mercury $(\mathrm{Hg})$ which has exceeded the quality standard. Simulations of lead $(\mathrm{Pb})$ and Mercury $(\mathrm{Hg})$ show the longer time $(\mathrm{t})$, constant pollutant inputs make the contaminant load even greater. As a result, the concentration of contaminants at a larger $t$ will decrease further. Simulation results of lead $(\mathrm{Pb})$ and mercury $(\mathrm{Hg})$ concentrations have reached a distance of \pm 100 Meters from landfill contaminants continue to spread as we age TPA, lead $(\mathrm{Pb})$ and mercury $(\mathrm{Hg})$ contaminants have reached the Batang Lembang river which is \pm 2500 Meters from TPA, and decreases at a greater distance.

Keywords: Landfill, leachate, Lead, Mercury, Advection, Dispersion 


\section{PEndahuluan}

Tempat Pemrosesan Akhir Sampah (TPA) merupakan tempat untuk menampung pembuangan sampah dari berbagai lokasi, yang biasa cakupannya adalah satu kota. Penyingkiran dan pemusnahan sampah ke dalam tanah merupakan cara yang selalu digunakan, karena biaya relatif murah, pengoperasiannya mudah dan luwes dalam menerima limbah [1]. Namun dengan menyingkirkan sampah ke TPA bukan berarti masalahnya sudah selesai, karena TPA yang tidak dikelola dengan baik akan menimbulkan masalah baru timbulan limbah cair lindi yaitu berpotensi mencemari air tanah maupun air sungai [2]. Kontaminan bisa terbawa oleh pergerakan air lindi melalui tanah, dapat mengkontaminasi tanah, air tanah, dan air sungai.

TPA menjadi tempat penampungan berbagai macam sampah sehingga lindi mengandung berbagai jenis bahan pencemar yang berpotensi mengganggu lingkungan dan kesehatan manusia. Setiap TPA memiliki karakteristik air lindi yang berbeda tergantung dari proses yang terjadi di dalam landfill, yang meliputi proses fisika, kimia dan biologis. Umumnya lindi mengandung Chemical Oxygen Demand (COD), Biology Oxygen Demand (BOD), Total dissolved solids (TDS), total organic carbont (TOC), senyawa nitrogen dan berbagai jenis logam berat yang tinggi[3]. Air lindi tersebut dapat merembes ke dalam tanah, ataupun mengalir di permukaan tanah dan bermuara pada aliran air sungai[4].

TPA Regional Kota Solok terletak di ampang kualo kelurahan kampung jawa Kota Solok dengan luas areal $8 \mathrm{Ha}$. TPA ini mulai beroperasi sebelumnya lalu pada tahun 2014 menjadi TPA regional kota Solok yang menerima sampah yang berasal dari kota dan kabupaten yang dilayani oleh TPA Sampah Regional Solok. Pengelolaan sampah di TPA regional kota Solok ini masih menggunakan sistem controlled landfill yaitu satu sistem dimana secara periodik sampah yang telah tertimbun ditutup dengan lapisan tanah untuk mengurangi potensi gangguan lingkungan. Akan tetapi metode pembuangan sampah ini masih berpotensi mencemari lingkungan

TPA Regional Kota Solok diindikasikan akan menjadi salah satu sumber pencemar yang memberikan kontribusi terhadap penurunan kualitas air sungai. Hal tersebut dapat diketahui secara lansung dengan melihat kondisi badan air sungai yang terletak \pm 100 meter dari TPA Regional Kota Solok yang berwarna kehitaman dan mengeluarkan bau. Badan air ini selanjutnya akan bersatu dengan sungai Batang lembang yang merupakan sungai terbesar dan terpanjang yang mengalir membelah Kota Solok dari arah Utara ke Selatan.

Batang Lembang memiliki panjang 9,156 km dan terhubung secara langsung dengan aktivitas perkotaan. Selain dimanfaatkan untuk sumber air baku PDAM, kegiatan perikanan, maupun sebagai sarana MCK bagi segelintir masyarakat di sempadan sungai, tak dapat dipungkiri Sungai Batang Lembang juga menjadi muara dari limbah cair rumah tangga dan beberapa aktivitas usaha seperti bengkel, UKM tahu serta rumah sakit. Selanjutnya Sungai Batang Lembang akan bermuara ke Danau Singkarak. Oleh karena itu, perlu dilakukan penelitian untuk mengetahui pencemaran air sungai di sekitar TPA, terutama pencemaran logam berat yang merupakan polutan yang berbahaya bagi lingkungan karena termasuk salah satu polutan konservatif yang tidak mengalami perubahan (tidak terdegradasi, tidak hilang karena penguapan, atau akibat aktifitas lainnya) dimana konsentrasinya tidak berubah terhadap waktu [5] [6].

Untuk mengetahui Penyebaran kontaminan logam berat dari TPA Regional kota Solok yang telah terjadi dan jangka waktu yang diperlukan kontaminan untuk mengkontaminasi air sungai sawah lansek. Sehingga penulis tertarik untuk melakukan penelitian dengan judul "Studi Penyebaran Kontaminan Logam Berat Timbal (Pb) dan Merkuri (Hg) dari Air Lindi Terhadap Air Sungai (Studi Kasus TPA Regional Kota Solok).”

\section{METODE}

Lokasi penelitian dilakukan di TPA Regional Kota Solok yang terletak di Ampang Kualo Kelurahan Kampung Jawa Kota Solok. Dari survey awal, maka dipilih dua titik sampling setelah TPA dan satu titik kontrol yaitu outlet TPA untuk mengetahui bagaimana perubahan konsentrasi kontaminan sepanjang sungai sawah lansek. Lokasi titik sampling dapat dilihat pada Gambar 1.

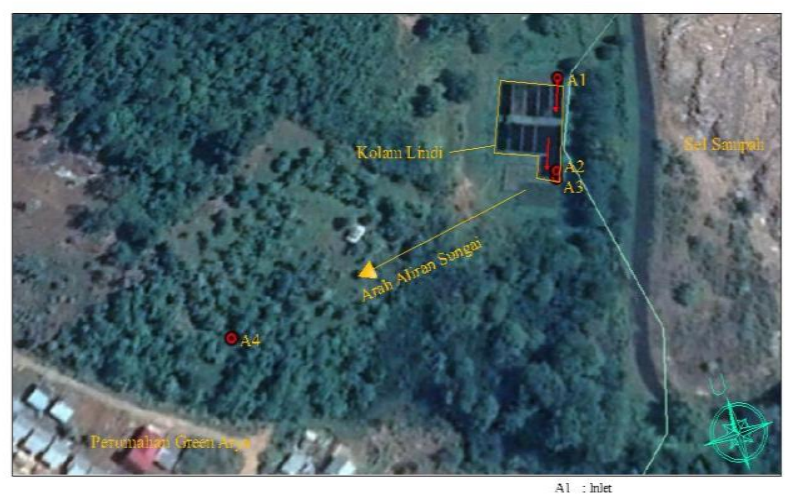

Gambar 1. Lokasi TPA 


\section{Pengumpulan Data Primer}

Pengumpulan data primer dilakukan dengan mengambil sampel lansung kelapangan. Kualitas badan air dianggap relative stabil sehingga pengambilan sampel air menggunakan metode grab sampleatau contoh air sesaat yaitu, yaitu contoh air diambil pada satu kali dari satu lokasi. Pengambilan sampel dilakukan pada 3 titik yang dianggap mewakili kondisi sungai. Data primer yan dikumpulkan antara lain data hidrogeometri sungai, konsentrasi $\mathrm{Pb}$ dan $\mathrm{Hg}$ dalam air sungai.

\section{Aplikasi Model}

Untuk mengetahui pergerakan kontaminan pada aliran sungai digunakan solusi analitis [7], model ini dikembangkan berdasarkan adveksi, dispersi dan reaksi sebagai berikut :

$\mathrm{R}=\frac{\partial c}{\partial t}=-\mathrm{v} \frac{\partial c}{\partial x}+\mathrm{DL} \frac{\partial^{2} c}{\partial x^{2}}+\mathrm{DT} \frac{\partial^{2} c}{\partial y^{2}}+\mathrm{Dv} \frac{\partial^{2} c}{\partial z^{2}}-\lambda$

Sedangkan dalam beberapa kasus,seperti misalnya kebocoran tangki bawah tanah yang berisi bahan beracun dan berbahaya, perembesan terus menerus dari lindi TPA, sumber kontaminannya lebih tepat dianggap sebagai injeksi terus-menerus atau kontinu. Domenico menyelesaikan satu solusi analitik untuk sumber kontaminan dengan injeksi kontinu yang berbentuk bidang [7]. Solusi tersebut di tulis:

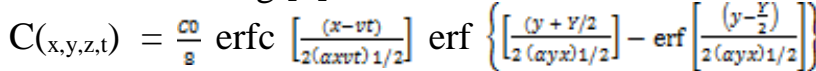

$$
\begin{aligned}
& \operatorname{erf}\left[\frac{(z-z)}{2(a z x) 1 / 2}\right]-\operatorname{erf}\left[\frac{(z-Z)}{2(a z x) 1 / 2}\right] \ldots
\end{aligned}
$$

\section{HASIL DAN PEMBAHASAN}

\section{Data Lapangan}

Permodelan tranfer kontaminan yang berdasarkan pada persamaan adveksi-disperi sangat membutuhkan data lapangan. Dari sampling pertama data lapangan yang di dapatkan terdiri dari pengukuran karakteristik saluran (lebar sungai, kedalaman sungai serta kecepatan aliran sungai). Data tersebut diolah sehingga didapat debit aliran sungai.

Pada saat pengambilan data kondisi di lapangan cerah, maka dengan mengunakan data tersebut model tidak valid dalam kondisi hujan. Hal terebut dikarenakan pada saat kondisi hujan akan ada pengenceran konsentrasi dan perubahan debit yang cukup besar.

Gambar 2 memperlihatkan hasil pengukuran $\mathrm{Pb}$ dan $\mathrm{Hg}$ pada titik 1 yaitu outlet konentrasi $\mathrm{Pb}$ telah melebihi baku mutu Permen.LH No. 5 tahun 2014 dengan nilai $0.315 \mathrm{mg} / \mathrm{l}$. Setelah melewati outlet yaitu dititik 2 konsentrai $\mathrm{Pb}$ mengalami penurunan tetapi masih melewati baku mutu dengan nilai 0.117 $\mathrm{mg} / \mathrm{l}$. Dan pada titik 3 konsentrasi $\mathrm{Pb}$ mengalami penurunan yang cukup jauh yaitu $0.043 \mathrm{mg} / \mathrm{l}$ dan sudah di bawah baku mutu.

Pola perubahan konsentrasi $\mathrm{Hg}$ dalam air berbeda dengan konsentrasi $\mathrm{Pb}$ yaitu pada titik 1 yaitu outlet konsentrasi $\mathrm{Hg}$ telah melebihi baku mutu Permen.LH No. 59 tahun 2016 yaitu dengan nilai $0.102 \mathrm{mg} / \mathrm{l}$. Setelah melewati outlet dititik 2 konsentrai $\mathrm{Hg}$ mengalami penurunan tetapi masih melewati baku mutu dengan nilai $0.088 \mathrm{mg} / \mathrm{l}$. Pada titik 3 konsentrasi $\mathrm{Hg}$ mengalami penurunan yang cukup jauh yaitu $0.02 \mathrm{mg} /$ letapi masih melebihi baku mutu.

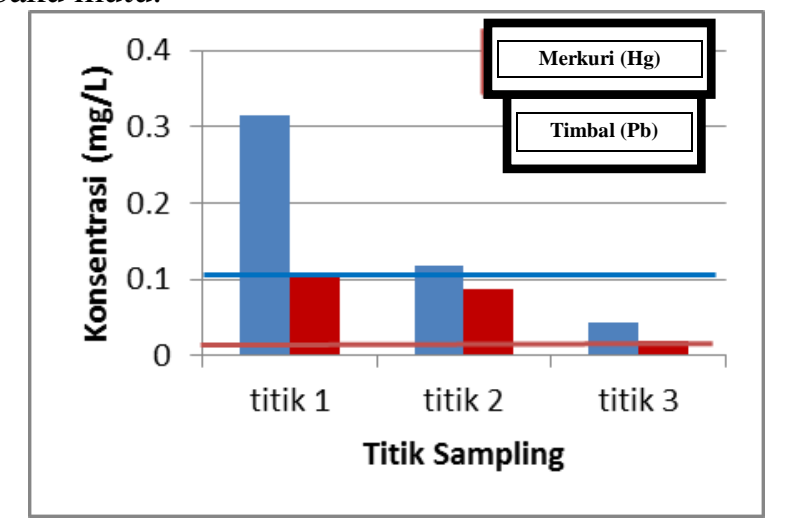

Gambar 2. Hasil Pengukuran Konsentrasi Pb dan Hg

\section{Prediksi 1-D Timbal (Pb)}

Prediksi dilakukan untuk mengetahui sejauh mana kontaminan $\mathrm{Pb}$ sudah menyebar di air tanah pada waktu tertentu. Prediksi dilakukan secara satu dimensi dalam waktu 4 tahun. Gambar 3 menunjukan prediksi penyebaran kontaminan $\mathrm{Pb}$.

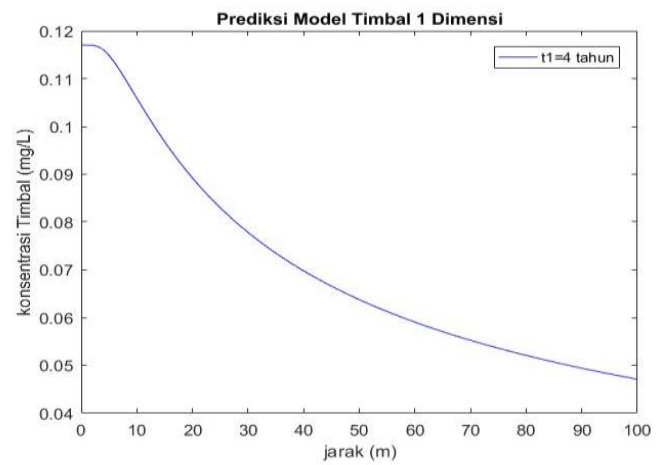

Gambar 3 Prediksi Satu Dimensi Timbal (Pb)

Gambar 3 menunjukkan prediksi simulasi $\mathrm{Pb}$ satu dimensi ketika usia operasional TPA 4 tahun. Konsentrasi dan jarak penyebaran $\mathrm{Pb}$ diprediksi meningkat sesuai bertambahnya usia operasional TPA. Pada prediksi waktu 4 tahun semenjak TPA beroperasi kontaminan $\mathrm{Pb}$ telah menyebar sampai \pm $100 \mathrm{~m}$ yaitu telah mencapai titik observasi yaitu aliran badan air dekat perumahan warga yan berjarak \pm 50 meter dari TPA. 
Model Penyebaran Kontaminan Timbal (Pb)2-D

Simulasi model dilakukan secaradua dimensi dengan waktu 4 tahun sesuai dengan umur TPA Sampah Regional Kota Solok.Parameter utama yang mempengaruhi perubahan persebaran kontamianan pada aliran air adalah proses adveksi,disperse dan retardasi.Berdasarkan hasil simulasi model, menunjukkan bahwa persebaran kontaminan $\mathrm{Pb}$ telah menyebar pada aliran badan air. Gambar 4 menunjukan simulasi model dua dimensi penyebaran $\mathrm{Pb}$ pada aliran badan air.

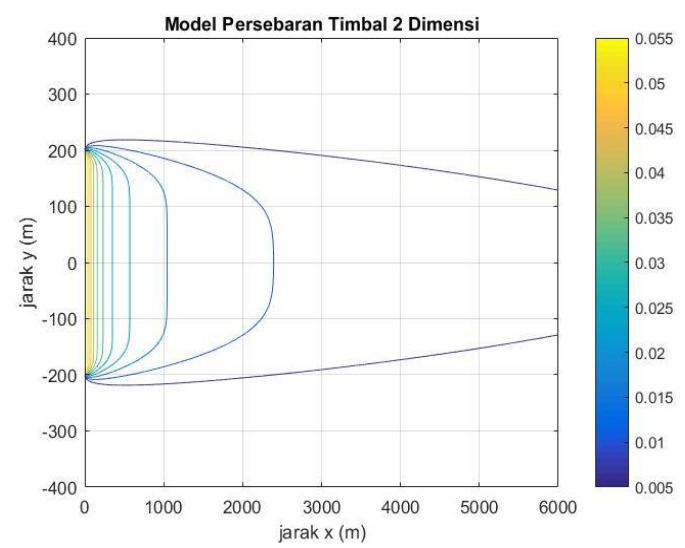

Gambar 4 Hasil Simulasi Dua Dimensi Timbal (Pb)

Berdasarkan simulasi model 2 dimensi dapat disimpulkan bahwa pencemar menyebar mencapai jarak $\pm 100 \mathrm{~m}$ dari TPA. Hasil simulasi telah menjangkau jarak titik observasi terdekat yaitu aliran sungai yang berada disekitar perumahan penduduk terdekat, dan dapat dilihat pada jarak 6000 $\mathrm{m}$ kontaminant $\mathrm{Pb}$ masih ada dengan konsentrasi yang berkurang menjadi $\pm 0.005 \mathrm{Mg} / \mathrm{L}$ dan berdasarkan simulasi kontaminan telah menjangkau titik observasi sungai Batang Lembang yang berjarak $\pm 2500 \mathrm{~m}$ dari TPA Regional Kota Solok.

\section{Prediksi 1-D Merkuri (Hg)}

Prediksi dilakukan untuk mengetahui sejauh mana kontaminan $\mathrm{Hg}$ sudah menyebar di badan air pada waktu tertentu. Prediksi dilakukan secara satu dimensi dalam waktu 4 tahun. Gambar 5 menunjukan prediksi penyebaran kontaminan $\mathrm{Hg}$.

Gambar 5 menunjukkan prediksi simulasi $\mathrm{Hg}$ satu dimensi ketika usia operasional TPA 4 tahun. Konsentrasi dan jarak penyebaran $\mathrm{Hg}$ diprediksi meningkat sesuai bertambahnya usia operasional TPA .Pada prediksi waktu 4 tahun semenjak TPA beroperasi kontaminan $\mathrm{Hg}$ telah menyebar sampai \pm $100 \mathrm{~m}$ yaitu telah mencapai titik observasi yaitu aliran badan air dekat perumahan warga yan berjarak \pm 50 meter dari TPA.

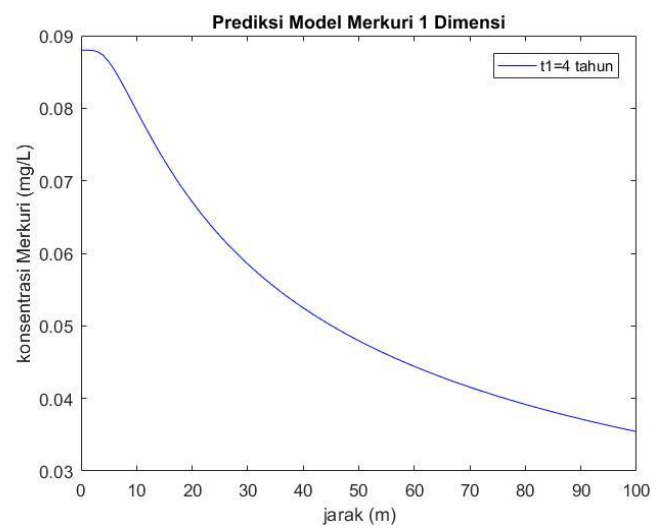

Gambar 5 Prediksi Satu Dimensi Merkuri (Hg)

Model Penyebaran Kontaminan Merkuri (Hg)2D

Simulasi model dilakukan secara dua dimensi dengan waktu 4 tahun sesuai dengan umur TPA Sampah Regional Kota Solok.Parameter utama yang mempengaruhi perubahan persebaran kontamianan pada aliran air adalah proses adveksi, dispersidan retardasi .Berdasarkan hasil prediksi model, menunjukkan bahwa persebaran kontaminan $\mathrm{Hg}$ telah menyebar pada aliran badan air. Gambar 6 menunjukan simulasi model dua dimensi penyebaran $\mathrm{Hg}$ pada aliran badan air.

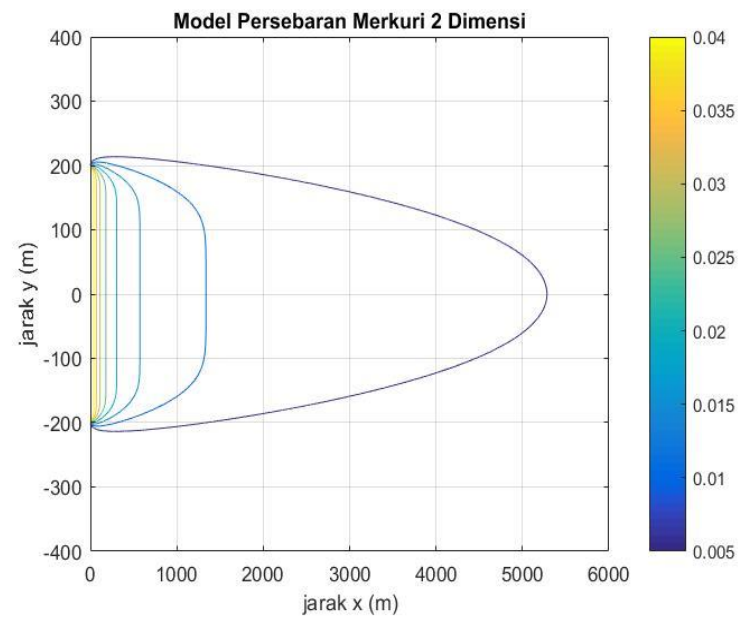

Gambar 6. Hasil Simulasi Dua Dimensi Merkuri (Hg)

Berdasarkan simulasi model 2 dimensi dapat disimpulkan bahwa pencemar menyebar mencapai jarak $\pm 100 \mathrm{~m}$ dari TPA. Hasil simulasi telah menjangkau jarak titik observasi terdekat yaitu aliran sungai yang berada disekitar perumahan penduduk terdekat, dan dapat dilihat pada jarak 5000 $\mathrm{m}$ kontaminan $\mathrm{Hg}$ masih ada dengan konsentrasi yang berkurang menjadi $\pm 0.005 \mathrm{mg} / \mathrm{L}$ dan berdasarkan simulasi kontaminan telah menjangkau titik observasi sungai Batang Lembang yang berjarak $\pm 2500 \mathrm{~m}$ dari TPA Regional Kota Solok. 


\section{KESIMPULAN}

Lindi yang dihasilkan TPA Kota Solok telah melebihi baku mutu yang ditetapkan oleh Peraturan Menteri Lingkungan Hidup RI Nomor 5 Tahun 2014 tentang baku mutu air limbah bagi usaha dan/atau kegiatan yang belum memiliki baku mutu air limbah yang ditetapkan,yaitu parameter logam berat Timbal $(\mathrm{Pb})$ yang terukur $0,315 \mathrm{mg} / \mathrm{L}$, sedangkan parameter logam berat Timbal $(\mathrm{Pb})$ yang ditetapkan baku mutu adalah $0,1 \mathrm{mg} / \mathrm{L}$ dan untuk parameter logam berat Merkuri $(\mathrm{Hg})$ yang terukur pada air lindi sebesar $0,102 \mathrm{mg} / \mathrm{L}$, dan telah melebihi baku mutu Nomor P.59/Menlhk/Setjen/Kum.1/7/2016 tentang baku mutu lindi bagi usaha dan/atau kegiatan tempat pemrosesan akhir sampah.

Sungai yang terdekat dari lokasi TPA Regional Kota Solok adalah parit alam yang bersatu ke Sungai Batang lembang yang berjarak 2,4 Km, dan memiliki kecepatan aliran $0,064 \mathrm{~m} / \mathrm{s}$ serta debit aliran 0,0113 $\mathrm{m}^{3} / \mathrm{s}$.

Pergerakan kontaminan pada aliran badan air dipengaruhioleh adveksi, dispersivitas, dan factor reterdasi kontaminan.Penyebaran kontaminan $\mathrm{Pb}$ yang berasal dari lindi TPA telah mencapai sungai pada jarak \pm 100 meter dari TPA, dan Penyebaran kontaminan $\mathrm{Hg}$ telah mencapai sungai pada jarak \pm 100 meter dari TPA. Kontaminan terus menyebar seiring bertambahnya umur TPA, kontaminan $\mathrm{Pb}$ dan $\mathrm{Hg}$ telah mencapai titik observasi kedua yaitu sungai Batang Lembang yang berjarak $\pm 2500 \mathrm{~m}$ dari TPA Regional Kota Solok.

\section{DAFTAR PUSTAKa}

[1] D. Enri and T. Padmi, Pengelolaan Sampah Terpadu. Bandung: ITB, 2016.

[2] F. Lü et al., "Dissolved organic matter and estrogenic potential of landfill leachate," Chemosphere, vol. 72, no. 9, pp. 1381-1386, 2008.

[3] Y. Arbi and E. R. Aidha, "SIMULATION OF MERCURY TRANSPORT FROM GOLD MINING ACTIVITIES IN PELAWAN RIVER, SAROLANGUN,” 2017, vol. 4, pp. 567-571.

[4] Y. Arbi, R. Siregar, and Tri Padmi Damanhuri, "KAJIAN PENCEMARAN AIR TANAH OLEH LINDI DI SEKITAR AIR DINGIN KOTA PADANG," SAINS DAN Teknol. STTIND PADANG, vol. 18, no. 1, 2018.

[5] M. M. Chow, S. S. Cardoso, and J. M. Holford, Dispersion of Pollutants Dicharged Into the Ocean: The Interaction of Small and Large Scale Phenomena. University of Cambridge, UK: Departement of chemical Engineering \& Departementof Applied Mathematics and Theoretical Physics, 2003.

[6] Republik Indonesia, "Undang-Undang No. 18. Tahun 2018 tentang Pengelolan Sampah. Lembaran Negara RI Tahun 2018, No 69,” Jakarta, 2018.

[7] P. Domenico and F. Schwartz, Physical and chemical hydrogeology. Ney York: John Wiley \& Sons, Inc., 1990. 